\title{
Erratum to: A benchmark for RNA-seq quantification pipelines
}

Mingxiang Teng ${ }^{1,2,8}$, Michael I. Love ${ }^{1,2}$, Carrie A. Davis ${ }^{3}$, Sarah Djebali $^{4}$, Alexander Dobin $^{3}$, Brenton R. Graveley ${ }^{5}$, Sheng Li ${ }^{6}$, Christopher E. Mason ${ }^{6}$, Sara Olsonn, Dmitri Pervouchine ${ }^{4}$, Cricket A. Sloan ${ }^{7}$, Xintao Wei ${ }^{5}$, Lijun Zhan ${ }^{5}$ and Rafael A. Irizarry ${ }^{1,2^{*}}$

After the publication of this work [1] it was noticed that there were typographical errors in the following equations: equation 5 in column 2, equation 7 in column 2, equation 8 in column 1.

The bracket was placed incorrectly, so it should read:

$\mid \log _{-} 2\left(Y_{-}\{g i j\}+0.5\right)$ rather thank ( $\log \_2_{\text {Y }}\{\{\mathrm{gij}\}+0.5)$

The publisher apologizes for this error.

\begin{abstract}
Author details
'Department of Biostatistics and Computational Biology, Dana-Farber Cancer Institute, 450 Brookline Avenue, Boston, MA 02215, USA. ²Department of Biostatistics, Harvard TH Chan School of Public Health, 677 Huntington Avenue, Boston, MA 02115, USA. ${ }^{3}$ Functional Genomics Group, Cold Spring Harbor Laboratory, 1 Bungtown Road, Cold Spring Harbor, NY 11724, USA. ${ }^{4}$ Bioinformatics and Genomics Programme Centre for Genomic Regulation (CRG) and UPF, Doctor Aiguader, 88, Barcelona 08003, Spain. ${ }^{5}$ Department of Genetics and Genome Sciences, Institute for System Genomics, UConn Health Center, Farmington, CT 06030, USA. ${ }^{6}$ Department of Physiology and Biophysics, Weill Cornell Medical College, New York, New York, USA. ${ }^{7}$ Department of Genetics, Stanford University, 300 Pasteur Drive, MC-5477, Stanford, CA 94305, USA. ${ }^{8}$ School of Computer Science and Technology, Harbin Institute of Technology, Harbin, China.
\end{abstract}

Received: 13 May 2016 Accepted: 13 May 2016

Published online: 23 May 2016

\section{Reference}

1. Teng M, Love MI, Davis CA, Djebali S, Dobin A, Graveley BR, et al. A benchmark for RNA-seq quanitification pipelines. Genome Biol. 2016;17:74.

\footnotetext{
* Correspondence: rafa@jimmy.harvard.edu

'Department of Biostatistics and Computational Biology, Dana-Farber Cancer Institute, 450 Brookline Avenue, Boston, MA 02215, USA

${ }^{2}$ Department of Biostatistics, Harvard TH Chan School of Public Health, 677 Huntington Avenue, Boston, MA 02115, USA

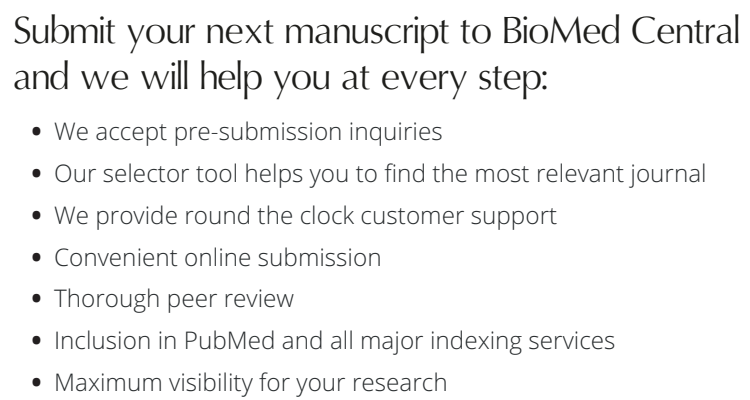

- We accept pre-submission inquiries

- Our selector tool helps you to find the most relevant journal

- We provide round the clock customer support

- Convenient online submission

- Thorough peer review

- Inclusion in PubMed and all major indexing services

- Maximum visibility for your research

Submit your manuscript at www.biomedcentral.com/submit 